\title{
若年者における高次波面収差の検討
}

\author{
関口沙知子 ${ }^{1)} \cdot$ 伊藤美沙絵 $\left.{ }^{1}\right)^{2)} \cdot$ 矢野 隆 ${ }^{3)} \cdot$ 相澤 大輔 ${ }^{1}$ \\ 鈴木 雅信 ${ }^{1)} \cdot$ 庄司 信行 $^{11}{ }^{2)} \cdot$ 㑭里 博 ${ }^{2)} \cdot$ 清水 公也 ${ }^{1}$ \\ 1) 北里大学病院眼科・2) 北里大学医療衛生学部, \\ 3) 国際医療福祉大学保健学部
}

\section{Investigation of higher-order wavefront aberrations in childhood}

\author{
Sachiko Sekiguchi ${ }^{1)}$, Misae Ito ${ }^{1)}{ }^{2)}$, Takashi Yano $^{3)}$, Daisuke Aizawa ${ }^{1)}$ \\ Masanobu Suzuki ${ }^{1)}$, Nobuyuki Shoji ${ }^{1{ }^{12}}{ }^{2)}$, Hiroshi Uozato ${ }^{2)}$, Kimiya Shimizu ${ }^{1)}$ \\ 1) Department of Ophthalmology, Kitasato University Hospital \\ 2) Department of Orthoptics and Visual Science, School of Allied Health Sciences, Kitasato University \\ ${ }^{3)}$ Department of Orthoptics and Visual Science, The School of Health Science, International \\ University of Health and Welfare
}

\begin{abstract}
要 約
目的：若年者の角膜と眼球全体の高次波面収差について検討した。

対象と方法：屈折異常以外に眼科学的疾患を認めない 4 歳から20歳までの81名134眼を対象とした。 収差測定にはHartmannーShack波面センサーを内蔵するKR-9000PW ${ }^{\mathrm{TM}}$ (TOPCON社製) を用いた。 また解析にはZernike多項式を用いてコマ様収差、球面様収差、全高次収差について検討した。 結果：角膜のコマ様収差は、年齢と負の相関（Spearmanの順位相関 : $\mathrm{r}=-0.383, \mathrm{p}<0.0001 ） を$ し、球面様収差は正の相関 $(\mathrm{r}=0.241, \mathrm{p}=0.0087)$ 、全高次収差は負の相関 $(\mathrm{r}=-0.286, \mathrm{p}=0.0019)$ を示した。眼球全体のコマ様収差、球面様収差、全高次収差は年齢と相関関係は認められなかった。 結論：若年者において角膜高次波面収差は年齢とともに減少した。
\end{abstract}

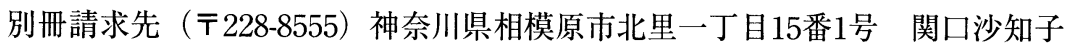
Tel. 042-778-8111 Fax. 042-778-9371

Key words : Higher-order Aberration, Childhood, aging, corneal aberration, ocular aberration 高次波面収差、若年者、年齢、角膜、眼球全体 


\begin{abstract}
Purpose : To investigate whether higher order wavefront aberrations of the cornea and the ocular vary with aging in childhood.

Subjects and methods: One hundred thirty four eyes of eighty one normal subjects in age from 4 to 20 years were evaluated with a Hartmann-Shack wavefront sensor (KR9000-PW ${ }^{\mathrm{TM}}$; Topcon). The data were analyzed quantitatively by expanding the sets of Zernike polynomials (S3,S4,S5,S6) in the central 6-mm zone. Terms of evaluation were Coma-like aberration, Spherical-like aberration, and total higher order aberrations.

Results : Corneal Coma-like aberration (Spearman rank correlation coefficient : $r=-0.383, p<0.0001$ ), Total higher order aberration $(r=-0.286, p=0.0019)$ were significantly negative correlated with aging where as Spherical-like aberration $(r=0.241, p=0.0087)$ were significantly positive correlated. The total ocular aberrations were not significantly correlated.

Conclusion : Corneal higher-order wavefront aberrations in youth were negatively correlated with aging.
\end{abstract}

\section{I．緒言}

これまでに成人以降の角膜と眼球全体の高次 波面収差は、年齢と正の相関を示すと報告され ている ${ }^{1)}$ 。しかし近年、若年者ではこの相関関 係が異なるとの報告がなされ2) 3 、成長途中の 若年者と成人において高次波面収差特性が異な る可能性が示唆された。しかし、これまでに若 年者の報告は少なく詳細な検討がなされていな いのが現状である。そこで今回、20歳以下の若 年者の角膜と眼球全体の高次波面収差について 検討したので報告する。

\section{II. 対象及び方法}

対象は、屈折異常以外に眼科学的疾患を認め ず、矯正視力 1.0 以上で収差測定時に自然瞳孔径 が $6 \mathrm{~mm}$ 以上確保できた 4 歳から 20 歳まで（平均 年齢 $10 \pm 4$ 歳）の81名 134 眼である。対象の球面 度数 $-0.24 \pm 3.37 \mathrm{D}$ 、円柱度数 $-0.62 \pm 0.38 \mathrm{D}$ 、角 膜乱視 $-1.12 \pm 0.45 \mathrm{D}$ であった（図 1 ）。

収差測定には、Hartmann-Shack波面センサ 一を内蔵のKR-9000PW ${ }^{\mathrm{TM}}$ （TOPCON社製）を 用いて、暗室かつ自然瞳孔にて行った。解析睹 孔径を $6 \mathrm{~mm}$ として、再現性のある各 3 回の平均 値を高次波面収差量として採用した。収差量は、 計測した波面をZernike展開して得られた係数の 2 乗の総和を求め、その平方根 root mean square
（RMS）として表示した。本装置での解析瞳孔 径 $6 \mathrm{~mm}$ ではZernike係数の 6 次まで解析可能で、 3 次と 5 次のRMSをコマ様収差、 4 次と 6 次の RMSを球面様収差、 3 次から 6 次までのRMSを 全高次収差として、角膜と眼球全体について検 討した。

\section{III. 結 果}

年齢と角膜乱視について検討した結果を図 1 に示す。角膜乱視は年齢と相関はみられなかっ た。(Spearmanの順位相関 $: \mathrm{r}=0.156, \mathrm{p}=$ 0.1267 図 1 )

年齢と角膜の高次波面収差について検討した結 果を図 $2 \mathrm{a} ， 2 \mathrm{~b} ， 2 \mathrm{c}$ に示す。コマ様収差は年 齢と負の相関がみられた（Spearmanの順位相 関 : $\mathrm{r}=-0.383, \mathrm{p}<0.0001$ 図 $2 \mathrm{a})$ 。球面様収差 は年齢と正の相関がみられた $(\mathrm{r}=0.241, \mathrm{p}=$ 0.0087 図 $2 \mathrm{~b})$ 。全高次収差は年齢と負の相関が みられた（ $r=-0.286, p=0.0019$ 図 $2 \mathrm{c})$ 。 年齢と眼球全体の高次波面収差について検討し た結果を 図 $3 \mathrm{a} ， 3 \mathrm{~b} ， 3$ cに示す。コマ様収差 $(\mathrm{r}=0.101, \mathrm{p}=0.4170$ 図 $3 \mathrm{a})$ 、球面様収差 $(r=$ $0.097, p=0.4748$ 図 $3 \mathrm{~b})$ 、全高次収差 $(r=0.128$, $\mathrm{p}=0.2014$ 図 $3 \mathrm{c}$ ）ともに年齢との相関は認めら れなかった。

また、若年者では眼球全体の高次波面収差量 が角膜の高次波面収差量より小さく推移した 


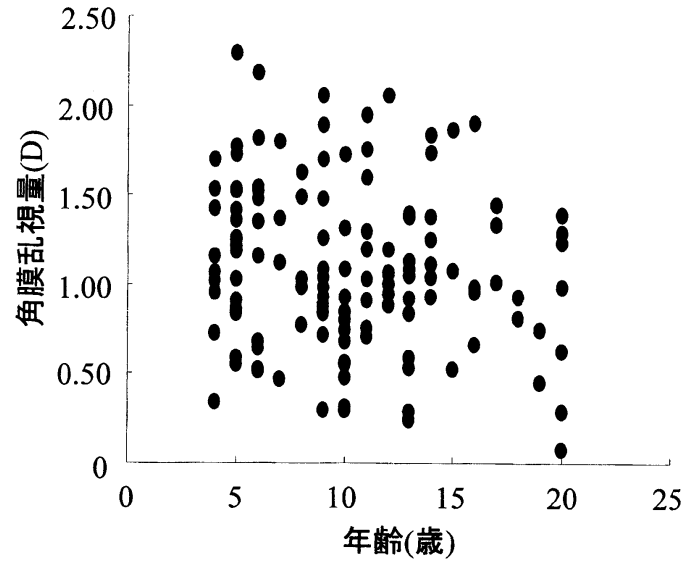

図 1 角膜乱視と年齢

横軸に年齢（歳）、縦軸に角膜乱視量（D）を 示す。

角膜乱視と年齢は相関がみられなかった。

$\mathrm{y}=0.0156 \mathrm{x}+1.2414$ (Spearmanの順位相関 : $\mathrm{r}=0.156, \mathrm{p}=0.1267$ )

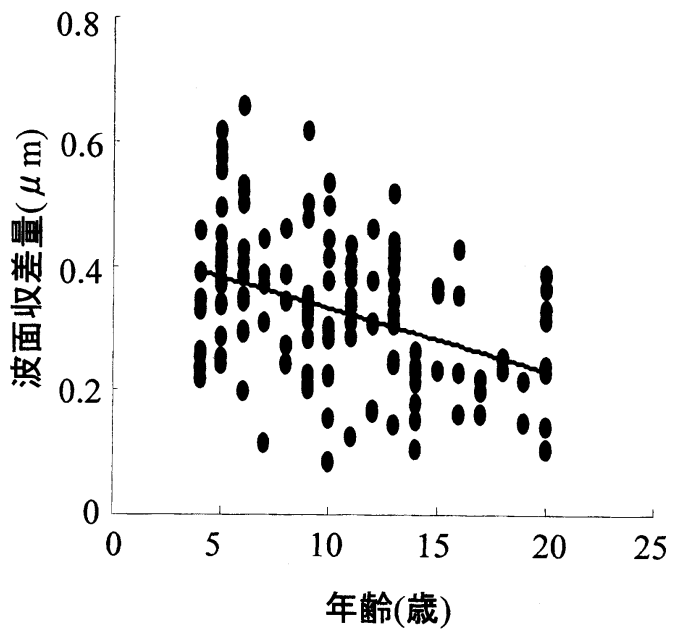

困 $2 \mathrm{a}$ 角膜コマ様収差と年齢（解析瞳孔径 $6 \mathrm{~mm}$ ) 横軸に年齢（歳）、縦軸に波面収差量（ $\mu$ m) を示す。

角膜コマ様収差と年齢は負の相関がみられ た。

$\mathrm{y}=-0.01 \mathrm{x}+0.4317$ (Spearmanの順位相関 : $\mathrm{r}=-0.383, \mathrm{p}<0.0001)$

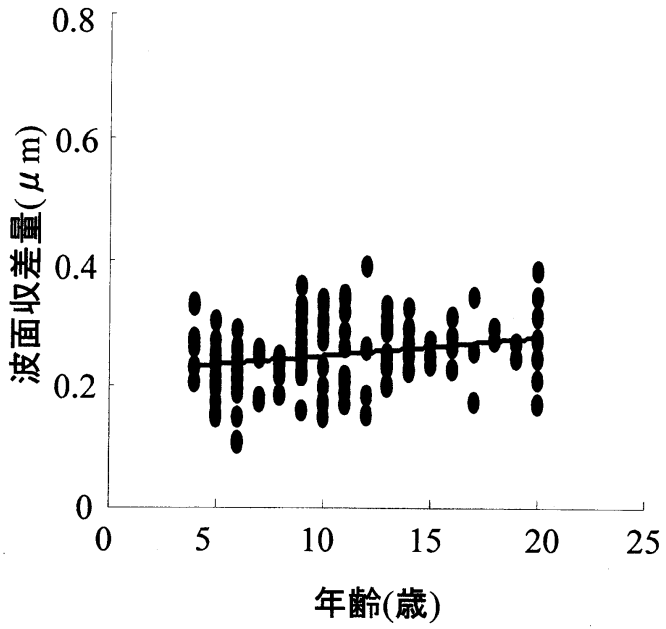

図 $2 \mathrm{~b}$ 角膜球面様収差と年齢 （解析瞳孔径 $6 \mathrm{~mm}$ ) 横軸に年齢（歳）、縦軸に波面収差量（ $\mu$ m) を示す。

角膜球面様収差と年齢は正の相関がみられ た。

$\mathrm{y}=0.003 \mathrm{x}+0.2164 （$ Spearmanの順位相関 : $\mathrm{r}=0.241, \mathrm{p}=0.0087)$

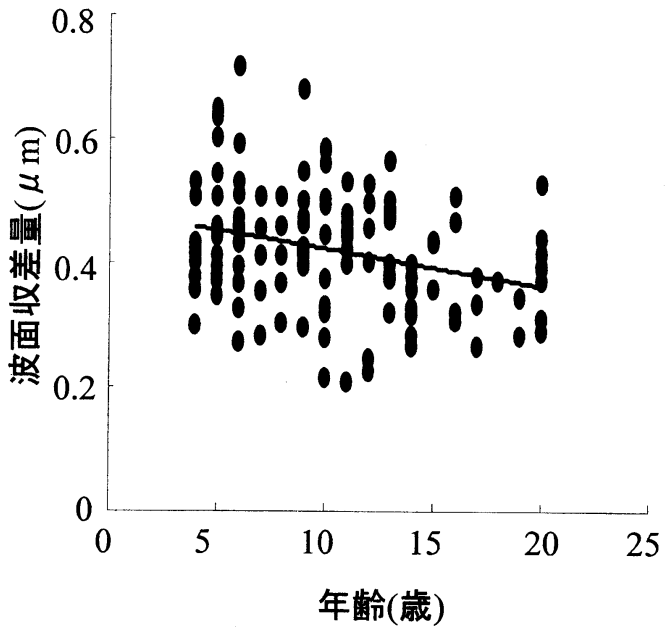

図 $2 \mathrm{c}$ 角膜全高次収差と年齢（解析瞳孔径 $6 \mathrm{~mm}$ ) 横軸に年齢（歳）、縦軸に波面収差量（ $\mu$ m) を示す。

角膜全高次収差と年齢は負の相関がみられ た。

$\mathrm{y}=0.003 \mathrm{x}+0.2164 \quad($ Spearmanの)順位相関 : $\mathrm{r}=-0.286, \mathrm{p}=0.0019)$ 


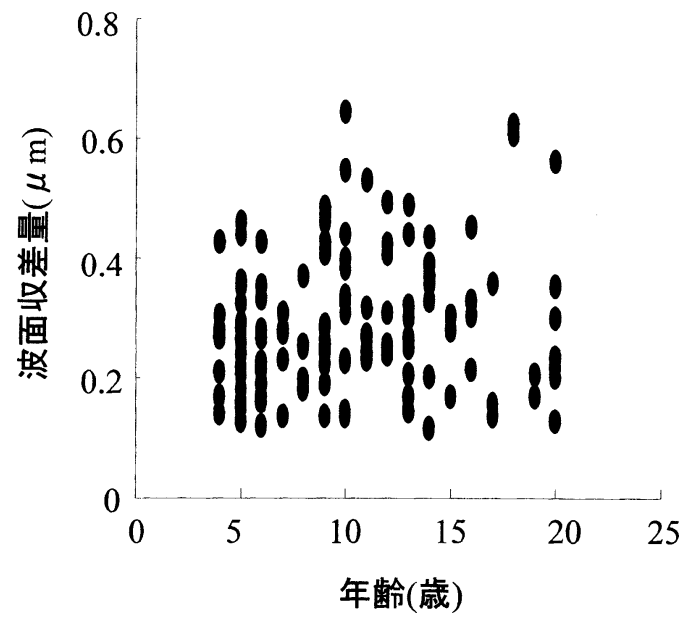

図 3 a 眼球全体のコマ様収差と年齡（解析睲孔径 $6 \mathrm{~mm}$ )

横軸に年齢（歳）、縦軸に波面収差量（ $\mu$ m) を示す。

$\mathrm{y}=0.0025 \mathrm{x}+0.2629$ (Spearmanの順位相関 :

$\mathrm{r}=0.101, \mathrm{p}=0.4170)$

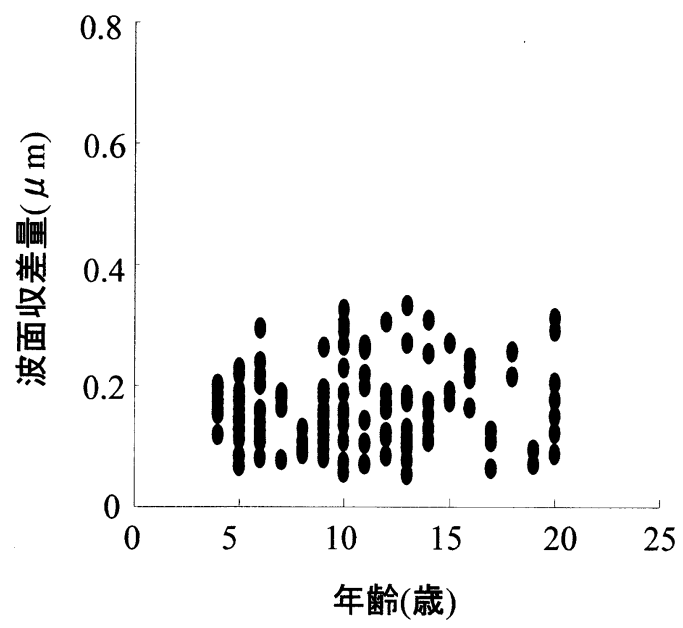

図 $3 \mathrm{~b}$ 眼球全体の球面様収差と年齢（解析曈孔径 $6 \mathrm{~mm})$

横軸に年齢（歳）、縦軸に波面収差量（ $\mu$ m) を示す。

$\mathrm{y}=0.0014 \mathrm{x}+0.1505$ (Spearmanの順位相関 : $\mathrm{r}=0.097, \mathrm{p}=0.4748$ )

（対応のあるt検定： $\mathrm{p}<0.0001$ 図 4 ）。

\section{IV.考按}

これまでに年齢と高次波面収差についてはす

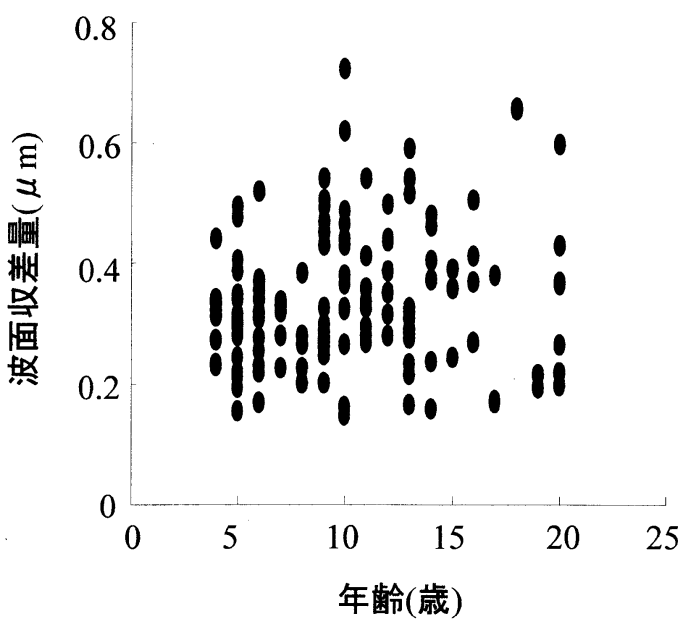

図 $3 \mathrm{c}$ 眼球全体の全高次収差と年齢（解析曈孔径 $6 \mathrm{~mm})$

横軸に年齢（歳）、縦軸に波面収差量（ $\mu$ m) を示す。

$\mathrm{y}=0.0033 \mathrm{x}+0.216 \quad($ Spearmanの順位相関 :

$\mathrm{r}=0.128, \mathrm{p}=0.2014$ )

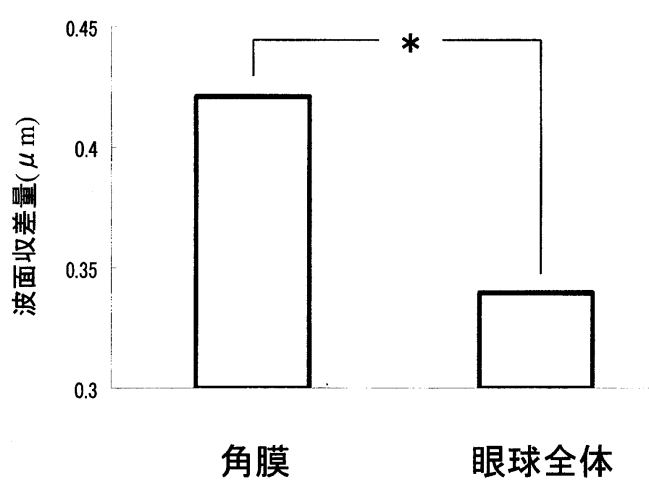

図 4 角膜と眼球全体の全高次収差（解析瞳孔径 6 $\mathrm{mm})$

縦軸に波面収差量（ $\mu \mathrm{m} ）$ を示す。

(対応のある $\mathrm{t}$ 検定 : $* \mathrm{p}<0.0001$ )

でに報告があり、角膜については、1999年に大 鹿 ${ }^{4)}$ らが年齢（9８5歳；102眼）と正の相関 があったことを報告し、2002年にArtal ${ }^{1)}$ ら（26 ～69歳；17眼）も同様の報告している。眼球全

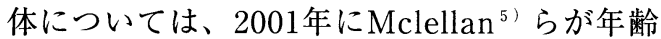
（22.9〜 64.5歳；38眼）と正の相関を報告し、 2002年のAltal ${ }^{1)}$ らも同様の報告をしている。し かし他の報告よりも年齢層を広げたBrunette ${ }^{2)}$ 
らの研究（ 5 ８2歳；114眼）では、眼球全体 の高次波面収差が年齢と 2 次関数様変化を示し、 37.5歳で最小值となるV字様の軌跡を示すと報告

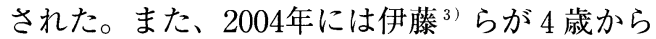
77歳までの150眼において、角膜のコマ様収差は 約25歳まで減少傾向を示し、40歳以降増加傾向 を示すことや角膜と眼球全体の高次波面収差が 多項式回帰を示すことを報告し、若年者と中年 から老年期の収差特性は眼球全体のみならず角 膜で異なる可能性を示唆している。つまり、成 人以降の報告ではすべて高次波面収差が年齢と 正の相関を示すとの同様の報告であるが、より 低年齢層を含めた研究では若干の相違がある。

今回の我々の研究では、角膜の高次波面収差 は年齢と負の相関を認め、伊藤 ${ }^{3)}$ らの報告と同 様な結果を得た。また、この変化は角膜高次波 面収差のコマ様収差でより著明であった。1996 年にFriedman ${ }^{6)}$ らは若年者の角膜乱視量は不変 であるが、角膜の形状がSteepからFlat化すると 報告している（6１4歳；788眼）。さらに中平 7) らは15歳頃にかけて眼軸が $24 \mathrm{~mm} に$ 近づく正 視化と平行して角膜がFlat化すると報告してい る。図1で示したように、対象の角膜乱視量は 年齢と相関を示さなかったにもかかわらず、角 膜の高次波面収差で年齢と相関関係を示したこ とは、角膜乱視量としては捉えることができな かった若年者の角膜の微細な形状変化を高次波 面収差として捉えたものと考えられる。また、 角膜のコマ様収差の減少からも角膜のFlat化に 伴う非対称性の減少と考えられるが、今回は角 膜形状変化について検討しておらず、今後検討 する必要性がある。また若年者で眼球全体の高 次波面収差変化を認めなかった。眼球全体の高 次波面収差は、角膜の高次波面収差と他の眼球 光学系で構成され、他の眼球光学系は主として 水晶体だと考えられている ${ }^{1)}{ }^{8)}$ 。水晶体の加齢 変化としては機能的には調節があり、形態的に は大きさ、形状、透明度、色調、蛍光などがあ る。特に収差増加の原因とされる形態的変化は 生涯変化し続け、30歳代を過ぎた頃から核部の 増大も著明となると報告されている ${ }^{9)}{ }^{10)}$ 。今回、 角膜の高次波面収差が年齢と負の相関を示し、 眼球全体の高次波面収差は変化を認めなかった
のは、他の眼球光学系 (主として水晶体) の収 差が年齢とともに増加したためと考えた。

さらにArtal ${ }^{1)}$ や伊藤 ${ }^{3)}$ らは、若年者の高次波 面収差は眼球全体よりも角膜のほうが大きく、 中年以降で逆転することを報告している。若年 者では大きな角膜高次波面収差を眼球内の他の 眼球光学系が補償し、眼球全体としての高次波 面収差量が抑えられているが、年龄変化に伴う 眼球内の高次波面収差増加によりその補償関係 が崩壊し、コントラスト感度の低下などの視力 の質の低下につながることが示唆されている。 今回、眼球全体の高次波面収差が角膜の高次波 面収差より小さく抑えられていることから、若 年者では良好な視力の質を維持している可能性 が示唆された。

\section{参考文献}

1) Artal P, Berrio E, Guirao A, Piers P: Contribution of the cornea and internal surfaces to the change of ocular aberrations with age. J Opt Soc Am A 19: 137-143, 2002.

2 ) Brunette I, Bueno J, Parent M, Hamam H, Simonet P: Monochromatic aberrations as a function of age, from childhood to advanced age. Invest Ophthalmol Vis Sci 44: 5438-5446, 2003.

3 ）伊藤美沙絵, 清水公也, 魚里 博, 矢野 隆, 他：高次波面収差の年齢変化. 日眼会誌 108 臨時増刊号：269，2004

4) Oshika T, Klyce S, Applegate R, Howland H: Changes in corneal wavefront aberrations with aging. Invest Ophthalmol Vis Sci 40: 1351-1355, 1999.

5 ) Mcllellan J, Marcos S, Burns S: Age-Related changes in monochromatic wave aberrations of the human eye. Invest Ophthalmol Vis Sci 42: 1390-1395, 2001.

6 ) Friedman N, Mutti D, Zadnik K: Corneal changes in schoolchildren. Optom Vis Sci 73: 552-557, 1996.

7 ）中平洋政：眼の屈折要素の経年変化 第 2 報. 眼紀 48：1031-1035，1997。 
8 ）黑田輝仁, 不二門 尚：加齢による収差の増 加と眼鏡処方. あたらしい眼科19：155-160： 2002.

9 ) Weale RA: Senescent visionis it all the fault of the lens?. Eye 1: 217-221, 1987.
10）大河内 浩之, 加藤 桂一郎, 梶田 雅義： 画像解析による水晶体の加齢変化. 眼臨96： $227-229: 2002$. 